\title{
Clinical feasibility of umbilical cord tissue-derived mesenchymal stem cells in the treatment of multiple sclerosis
}

Neil H. Riordan ${ }^{1,2^{*}}$, Isabela Morales², Giselle Fernández ${ }^{1}$, Nicole Allen ${ }^{3}$, Neal E. Fearnot ${ }^{3}$, Michael E. Leckrone ${ }^{4}$, Dedra Jones Markovich ${ }^{3}$, Darla Mansfield ${ }^{3}$, Dorita Avila ${ }^{2}$, Amit N. Patel ${ }^{5}$, Santosh Kesari ${ }^{6}$ and Jorge Paz Rodriguez

\begin{abstract}
Background: Multiple sclerosis (MS) is a progressively debilitating neurological condition in which the immune system abnormally erodes the myelin sheath insulating the nerves. Mesenchymal stem cells (MSC) have been used in the last decade to safely treat certain immune and inflammatory conditions.

Methods: A safety and feasibility study was completed on the use of umbilical cord MSC (UCMSC) as a treatment for MS. In this 1-year study, consenting subjects received seven intravenous infusions of $20 \times 10^{6}$ UCMSC over 7 days. Efficacy was assessed at baseline, 1 month and 1 year after treatment, including magnetic resonance imaging (MRI) scans, Kurtzke Expanded Disability Status Scale (EDSS), Scripps Neurological Rating Scale, Nine-Hole Peg Test, 25-Foot WalkTest, and RAND Short Form-36 quality of life questionnaire.

Results: Twenty subjects were enrolled in this study. No serious adverse events were reported. Of the mild AEs denoted as possibly related to treatment, most were headache or fatigue. Symptom improvements were most notable 1 month after treatment. Improvements were seen in EDSS scores $(p<0.03)$, as well as in bladder, bowel, and sexual dysfunction $(p<0.01)$, in non-dominant hand average scores $(p<0.01)$, in walk times $(p<0.02)$ and general perspective of a positive health change and improved quality of life. MRI scans of the brain and the cervical spinal cord showed inactive lesions in 15/18 (83.3\%) subjects after 1 year.
\end{abstract}

Conclusions: Treatment with UCMSC intravenous infusions for subjects with MS is safe, and potential therapeutic benefits should be further investigated.

Trial registration ClinicalTrials.gov NCT02034188. Registered Jan 13, 2014. https://clinicaltrials.gov/ct2/show/NCT02 034188

Keywords: Multiple sclerosis, Umbilical cord stem cells, Stem cell therapy, Multiple sclerosis treatment, Mesenchymal stem cells

\section{Background}

Multiple sclerosis (MS) is an immune-mediated inflammatory disease in which the immune system progressively destroys its own myelinated axons in the central nervous system, in episodes lasting from a few months to many years in duration. The eventual demyelination and

*Correspondence: nhriordan@gmail.com

1 Stem Cell Institute, Panama City, Panama

Full list of author information is available at the end of the article axonal degeneration can cause serious and debilitating motor, sensory, balance and cognitive problems, disability, serious complications, and negatively impact quality of life [1-3].

While there is no known cure for MS, up to $82 \%$ of costs incurred by MS patients are spent on drugs [4]. Treatments available include steroids for temporary flareups, disease-modifying drugs, and drugs targeting specific symptoms. While these may reduce the frequency of exacerbations and slow disease progression, none have 
myelin or nerve regenerative capability to restore the cumulative damage already in place [5].

Mesenchymal stem cells (MSC) derived from bone marrow, adipose, or other sources can exert inhibitory effects on immune-mediated disease states [6-10]. In particular, MSC derived from umbilical cord (UC) Wharton's Jelly possess a high proliferative and expansive ability, an enhanced therapeutic activity compared to other MSC [11-14], and superior production of growth factors that stimulate secretions responsible for therapeutic potential [15].

The safety of MSC therapy for MS has been demonstrated in several trials [16-20]. We reported three subjects treated with MSC and stromal vascular fraction with no adverse effects; all showed clinical improvements in cognitive and motor function and presented no new lesions on magnetic resonance imaging (MRI) [21]. More recently, trials with placenta-derived MSC [22], or with intravenous UCMSC [23] reported few mild or moderate adverse effects, as well as some improvement in Expanded Disability Status Scale (EDSS) scores.

In this study, we sought to determine the safety and the efficacy of allogeneic UCMSC treatment in subjects with MS.

\section{Methods}

This open-label, single-arm, single-center phase $1 / 2$ study was designed to assess the safety and efficacy of the intravenous administration of UCMSC for the treatment of MS. The study was approved by the Panamanian Institutional Review Board (Comité Nacional de Ética de la Investigación) and registered in the ClinicalTrials. gov database (NCT02034188). The study sponsor was Translational Biosciences. All treatments were administered at the Stem Cell Institute in the Republic of Panama, under Protocol Number TBS-UCMSC-001. Safety was defined as absence of treatment-associated adverse events at 1, 3 months, and 1 year post treatment. Efficacy was assessed with traditional MS evaluation instruments and a quality of life questionnaire at follow-up intervals, as detailed in the "Treatment protocol" section.

Subjects were enrolled under the following criteria: men or non-pregnant women ages 18-55 diagnosed according to revised McDonald criteria [24] for clinically-defined MS; an EDSS score of 2.0-7.0 assessed at least 3 months after the last acute attack of MS; willingness to keep a weekly diary and undergo observation for 1 year, and provision of documented health insurance in their home country. Enrolled subjects were not required to refrain from taking other medications or supplements prior to study entry.

Subjects were excluded if they presented active proliferative retinopathy, poorly controlled diabetes mellitus (glycosylated hemoglobin $\mathrm{HbA1C}>8.5 \%$ ), renal insufficiency (Creatinine $>2.5 \mathrm{mg} / \mathrm{dL}$ ) or failure, infection (white blood cell count of $>15,000 \mathrm{~K} /$ cumm and/or temperature $>38^{\circ} \mathrm{C}$ ), history of organ transplant, previous or active malignancy, or cardiovascular conditions. All participants provided written informed consent before study participation.

\section{Treatment protocol}

Complete medical history, medication history, and list of concomitant medications were collected from all subjects prior to any treatment. Subjects also underwent a complete physical examination, vital signs (heart rate, respiratory rate, temperature, and systolic and diastolic blood pressure), a 12-lead electrocardiogram (ECG), and laboratory testing (complete blood count, serum chemistry) at baseline. MS diagnosis was confirmed according to the revised McDonald criteria. Enrolled subjects received $140 \times 10^{6}$ UCMSC intravenously over the course of seven visits $\left(20 \times 10^{6}\right.$ UCMSC/day) separated by $1-4$ days. At each treatment visit, subjects were assessed for any adverse events experienced since their last visit, received a physical examination (vital signs pre- and post- infusion), and were reviewed for adverse events throughout the visit.

Follow-up visits, scheduled at 1, 3 month and 1 year post-treatment, could take place at either the Stem Cell Institute or near the subjects' place of residence, overseen by a licensed medical professional. At all follow-up visits, any adverse events experienced since last visit were reviewed, and subjects received a physical examination, laboratory tests and a 12-lead ECG. Any concomitant medications were reviewed.

Adverse events were reported in terms of their severity (mild, moderate, severe), relatedness (definitely, probably, possibly, not likely and unrelated), action taken (none, adjustment, interruption or discontinuation of treatment dosage), medications or therapy taken (drug therapy, non-drug therapy, or none), and outcome (not recovered/resolved, recovered/resolved, recovering/resolving, recovered/resolved with sequelae, fatal and unknown). Efficacy parameters were assessed at baseline, at 1 month, and at 1 year, and included time point measures for the Kurtzke Expanded Disability Status Scale (EDSS), the Scripps Neurological Rating Scale (SNRS), the Nine-Hole Peg Test (9HPT), the 25-Foot Walk Test (25FWT), and the RAND Short Form-36 (SF-36) quality of life (QOL) questionnaire.

Gadolinium-enhanced MRI scans of the brain and cervical spinal cord were taken at baseline and 1 year after treatment, and were examined by a single independent radiologist blinded to the intervention. 


\section{UCMSC preparation and culture}

UCMSC in this study were produced by MediStem Panama Inc. UCMSC were isolated from afterbirth tissue obtained after full-term, healthy births, donated by consenting mothers. After screening for infection and contamination, UCMSC were obtained from enzymatic digestion of Wharton's Jelly tissue after a primary culture process at $37{ }^{\circ} \mathrm{C}, 5 \% \mathrm{CO} 2$ during $24 \mathrm{~h}$. Cells were expanded using alpha-MEM (Gibco Life Technologies, Grand Island, NY), supplemented with 10\% FBS (USFDA approved, Gibco Life Technologies, Grand Island, NY), and $4 \mathrm{mM}$ GlutaMax (Gibco Life Technologies, Grand Island, NY) in triple flasks under normoxic conditions. Cells were assessed between passages two and three for meeting MSC criteria and absence of contamination. Each enzymatic digestion step was considered to be a passage. Cells were harvested after 5 passages (3-4 weeks after initiation of primary culture). MediStem Panama used the minimal criteria established by the Mesenchymal and Tissue Stem Cell Committee of International Society for Cellular Therapy [25]. Each lot was tested for sterility (fungus, mycoplasma, aerobes and anaerobes), endotoxin level below $3 \mathrm{EU} / \mathrm{ml}$, and viability after thawing higher than $75 \%$. The approved cells expressed surface molecules CD105, CD73 and CD90, and lacked expression of CD45 and CD34, as determined by flow cytometry. UCMSC were also tested for differentiation into adipocytes, chondroblasts, and osteoblasts in vitro using StemPro ${ }^{\circledR}$ media, and stained with oil red, alcian blue and alizarin red, respectively. Approved cells were suspended in a dextrose and saline solution for subsequent administration.

\section{Statistical analysis}

SYSTAT version 13.1 (SYSTAT Software Inc., San Jose, CA, USA) was used to analyze the data. Differences between baseline and follow-up scores were examined using paired t-tests, with Bonferroni and Dunn-Sidak corrections where applicable. A p-value of $\mathrm{p}<0.05$ was considered significant.

\section{Results}

Twenty subjects with MS provided informed consent and were enrolled into this feasibility study from October 10, 2014 to February 18, 2015. Mean age of enrollees was $41.15(\mathrm{SD}=9.29)$ years; $60 \%(12 / 20)$ were female (Table 1). Enrolled subjects were of multiple international origins, including the Republic of Panama. The mean disease duration of enrollees was 7.7 years. Fifteen subjects $(75 \%)$ had a diagnosis of relapsing-remitting MS, four $(20 \%)$ with primary progressive MS, and one (5\%) with secondary progressive
Table 1 Demographics of subjects in the study

\begin{tabular}{|c|c|}
\hline Demographic & $\mathrm{N}=20$ \\
\hline \multicolumn{2}{|l|}{ Age (years) } \\
\hline Mean (SD) & $41.15(9.29)$ \\
\hline (Range) & $(24-55)$ \\
\hline \multicolumn{2}{|l|}{ Gender } \\
\hline Male & $40 \%(8 / 20)$ \\
\hline Female & $60 \%(12 / 20)$ \\
\hline \multicolumn{2}{|l|}{ Diagnosis } \\
\hline Relapsing remitting MS & $75 \%(15 / 20)$ \\
\hline Primary progressive MS & $20 \%(4 / 20)$ \\
\hline Secondary progressive MS & $5 \%(1 / 20)$ \\
\hline \multicolumn{2}{|l|}{ Disease duration (years) } \\
\hline \multicolumn{2}{|l|}{ Mean $=7.7$} \\
\hline$<3$ & $25 \%(5 / 20)$ \\
\hline $4-6$ & $25 \%(5 / 20)$ \\
\hline $7-9$ & $30 \%(6 / 20)$ \\
\hline $10-12$ & $10 \%(2 / 20)$ \\
\hline $16-18$ & $5 \%(1 / 20)$ \\
\hline $19-21$ & $5 \%(1 / 20)$ \\
\hline \multicolumn{2}{|l|}{ Ambulation status } \\
\hline Wheelchair & $55 \%(11 / 20)$ \\
\hline Walker & $20 \%(4 / 20)$ \\
\hline Bilateral cane & $5 \%(1 / 20)$ \\
\hline Unilateral cane & $20 \%(4 / 20)$ \\
\hline No assistance & $45 \%(9 / 20)$ \\
\hline \multicolumn{2}{|l|}{ Origin } \\
\hline White/Caucasian & $65 \%(13 / 20)$ \\
\hline African Descent & $10 \%(2 / 20)$ \\
\hline Middle Eastern & $5 \%(1 / 20)$ \\
\hline $\begin{array}{l}\text { Other (1 each Hispanic, Brazilian, Panamanian, and multi- } \\
\text { racial: Hispanic/White/Native American) }\end{array}$ & $20 \%(4 / 20)$ \\
\hline
\end{tabular}

MS. Eleven subjects (55\%) required ambulation assistance (wheelchair, walker, or cane) at baseline. Five subjects $(25 \%)$ did not take any MS-specific medication over the course of the study, 10 (50\%) continued taking their usual MS medications, one (5\%) began using MSspecific medication during follow-up, and four (20\%) reduced their intake of MS-specific medication during follow-up.

All subjects received all of the infusions specified by the treatment protocol, and attended the 1- and 3-month visits. Nineteen subjects were followed for 1 year: the 1 -year visit was completed for $17 / 20$ subjects, two subjects partially completed the 1-year requirements. One subject was lost to follow-up.

All subjects survived the study, and there were no reported serious adverse events (AEs). None of the reported AEs (Table 2) required adjustment, interruption 
Table 2 Reported adverse events

\begin{tabular}{|c|c|c|c|c|c|c|c|c|c|}
\hline \multirow[t]{2}{*}{ Event } & \multirow[t]{2}{*}{ Count } & \multicolumn{3}{|c|}{ Severity } & \multicolumn{5}{|l|}{ Relatedness } \\
\hline & & Mild & Moderate & Severe & Not related & Not likely & Possibly & Probably & Definitely \\
\hline Headache & 19 & 18 & 1 & 0 & 1 & 1 & 16 & 1 & 0 \\
\hline Fatigue & 19 & 19 & 0 & 0 & 0 & 2 & 17 & 0 & 0 \\
\hline Cardiovascular & 8 & 8 & 0 & 0 & 2 & 2 & 4 & 0 & 0 \\
\hline Injury/accident & 8 & 6 & 2 & 0 & 8 & 0 & 0 & 0 & 0 \\
\hline Gastrointestinal & 4 & 2 & 2 & 0 & 1 & 2 & 1 & 0 & 0 \\
\hline Musculoskeletal & 4 & 4 & 0 & 0 & 1 & 3 & 0 & 0 & 0 \\
\hline Infection & 3 & 3 & 0 & 0 & 2 & 0 & 1 & 0 & 0 \\
\hline Feelings/sensations & 3 & 3 & 0 & 0 & 0 & 2 & 1 & 0 & 0 \\
\hline Dizziness & 2 & 2 & 0 & 0 & 1 & 1 & 0 & 0 & 0 \\
\hline Gynecological & 1 & 0 & 1 & 0 & 1 & 0 & 0 & 0 & 0 \\
\hline Skin disorder & 1 & 1 & 0 & 0 & 0 & 1 & 0 & 0 & 0 \\
\hline Total & 72 & 66 & 6 & 0 & 17 & 14 & 40 & 1 & 0 \\
\hline
\end{tabular}

or discontinuation of treatments. There were six moderate AEs, and 66 mild AEs. No AEs were ongoing at the 1-year follow-up visit. No AEs were classified as definitely related to study treatment. The most commonly reported AEs were headache (18 mild and one moderate), and fatigue (19 mild), classified as possibly related to treatment.

EDSS scores were recorded at baseline and 1 month post-treatment for all subjects; scores at 1 year were available for 17 of 20 subjects (Fig. 1). At baseline, EDSS scores ranged from 2.5-7.0, with a mean score of 5.23 $(\mathrm{SD}=1.50)$. At 1 month, the mean score decreased to $4.75(\mathrm{SD}=2.00)$, a mean reduction of $0.48(\mathrm{SD}=0.85)$ or about one category. Scores reduced further at the 1-year time point, to $4.62(\mathrm{SD}=2.72)$, a mean reduction of 0.68 $(\mathrm{SD}=1.49)$, a little more than one category. Differences were statistically significant at 1 month $(\mathrm{p}<0.03)$, and 1 year $(\mathrm{p}<0.04)$ when compared to baseline.

SNRS scores were recorded at baseline and 1 month post-treatment for all subjects; scores at 1 year were recorded for 17 of 20 subjects (Table 3 ). The SNRS total mean score rose slightly from $75.0(\mathrm{SD}=11.9)$ at baseline to $75.5(\mathrm{SD}=16.5)$ at 1 month post-treatment, and decreased to $73.5(\mathrm{SD}=19.5, \mathrm{~N}=17) 1$ year post-treatment. A statistically significant improvement $(\mathrm{p}<0.01)$ was seen for the bladder/bowel/sex dysfunction category at 1 month from the baseline assessment (Fig. 2). A statistically significant worsening was seen in the study group

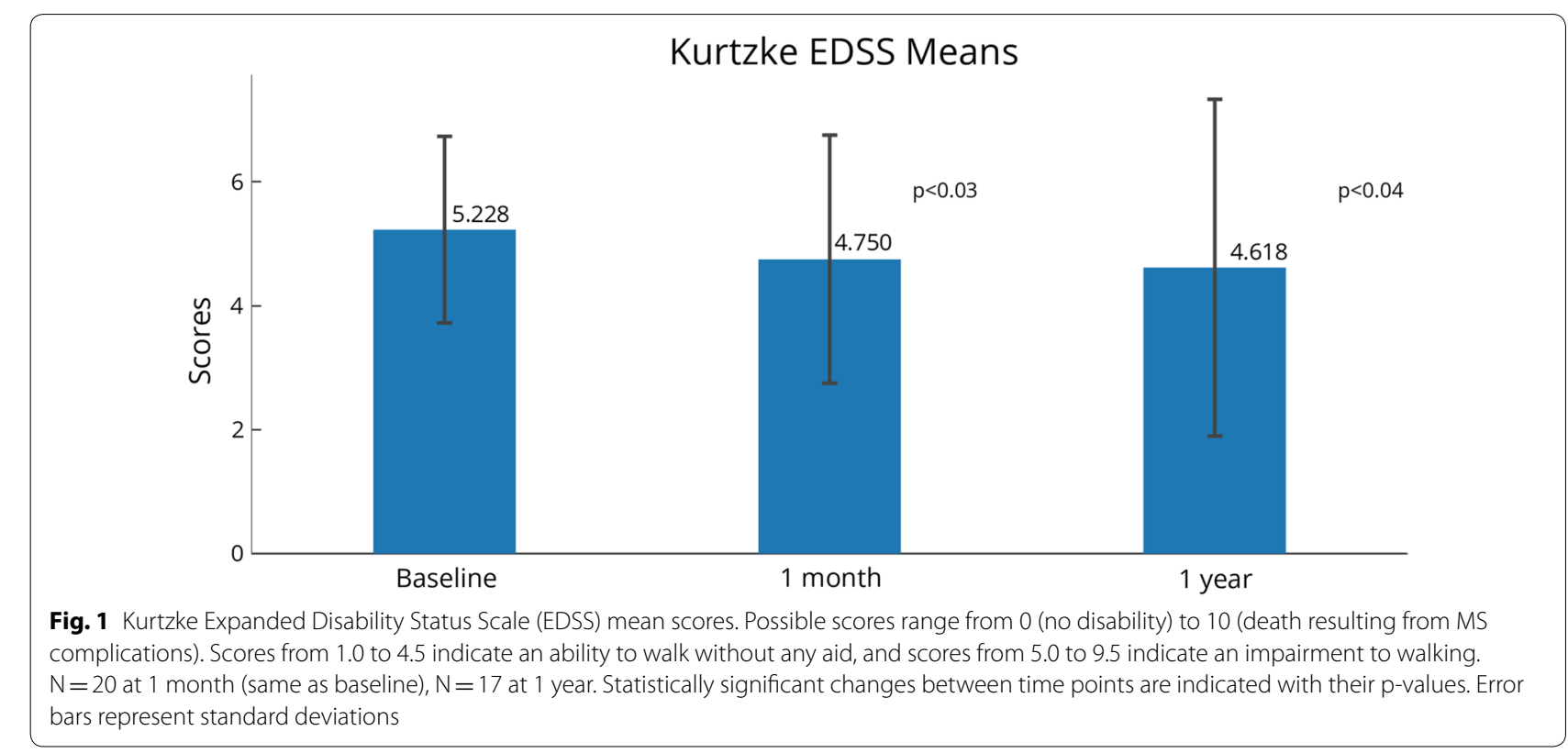


in four categories compared to baseline: visual acuity at 1 month $(\mathrm{p}<0.02)$ and 1 year $(\mathrm{p}<0.03)$, right upper extremity motor function at 1 year $(\mathrm{p}<0.02)$, right lower extremity sensory function at 1 month $(\mathrm{p}<0.03)$ and 1 year $(\mathrm{p}<0.01)$, and left lower extremity sensory function at 1 month $(\mathrm{p}<0.01)$.

The 9HPT was recorded for all subjects at baseline and 1 month post-treatment; scores were available for 19 of 20 subjects at 1 year (one lost to follow-up). Overall, subjects saw improvements in their scores. Statistically significant improvements from baseline were seen in non-dominant hand scores for both best $(\mathrm{p}<0.01)$ and average $(\mathrm{p}<0.02)$ times at the 1 -month assessment (Fig. 3). The best score for the non-dominant hand was $37.56 \mathrm{~s}$ at baseline, 32.49 at 1 month (5.1 s improvement), and 31.55 at 1 year (6.0 s improvement). The average mean score for the non-dominant hand was $40.80 \mathrm{~s}$ at baseline, 35.01 at 1 month (a $5.8 \mathrm{~s}$ improvement), and 34.09 (a $6.7 \mathrm{~s}$ improvement).

For the 25FWT, subjects were categorized into one of four categories, based on their need for assistance to complete the test (in order of increasing need): no assistance; cane; walker, and wheelchair. While scoring guidance for the 25FWT directs to use the average of the two completed trials, the minimum time was also analyzed to enable inclusion of any/all subject(s) who completed at least one full trial. At baseline, all 20 subjects were available for the $25 \mathrm{FWT}$, and 19 subjects were available at 1 month (one did not take the test). At 1 year, results were recorded for 17 subjects (two did not take the test; and one was lost to follow up). Some subjects were unable to complete one or both trials due to ambulation status (two were wheelchair-bound at baseline, one at the 1-month and at 1-year follow-ups), or fatigue (one subject was fatigued at the 1-year follow-up).

At baseline, average time for the 25FWT Trial 1 was $17.43 \mathrm{~s}$ and $17.51 \mathrm{~s}$ for Trial 2 (Table 4). Overall mean time was $17.47 \mathrm{~s}$, and average minimum time was $15.85 \mathrm{~s}$. One month after treatment, average walk time for Trial 2 improved by $6.01 \mathrm{~s}$, but average time for Trial 1 took longer than baseline, as did overall mean time, and average minimum time. At 1 year, all walk times were reduced when compared to baseline. Since not all subjects completed both trials of the 25FWT at a given time point, and not all subjects completed all follow-ups, statistical comparisons between baseline and follow-up scores could not include all subjects. Twelve subjects completed Trial 2 of the 25FWT at the three follow-up time points

Table 3 Scripps neurological rating system (SRNS) component scores

\begin{tabular}{|c|c|c|c|}
\hline SNRS component & Baseline & 1 month & 1 year \\
\hline Mentation and mood (normal $=10$ ) & $8.4(2.28)$ & $9.4(1.57)$ & $9.3(1.69)$ \\
\hline Visual acuity $(\text { normal }=5)^{*}$ & $4.9(0.45)$ & $4.2^{*}(1.35)$ & $4.2^{*}(1.24)$ \\
\hline Visual fields (normal=6) & $5.7(0.73)$ & $5.6(1.05)$ & $5.6(0.79)$ \\
\hline Eye movements (normal $=5$ ) & $4.8(0.62)$ & $4.8(0.62)$ & $4.8(0.66)$ \\
\hline Nystagmus (normal =5) & $5.0(0.00)$ & $4.8(0.62)$ & $4.9(0.49)$ \\
\hline Lower cranial nerves (normal =5) & $5.0(0.00)$ & $4.9(0.45)$ & $5.0(0.0)$ \\
\hline Motor function R upper extremity (normal $=5)^{*}$ & $4.8(0.62)$ & $4.5(0.89)$ & $4.1^{*}(1.44)$ \\
\hline Motor function L upper extremity (normal $=5$ ) & $4.3(0.98)$ & $4.4(1.14)$ & $4.1(1.44)$ \\
\hline Motor function R lower extremity (normal =5) & $3.2(1.66)$ & $2.6(1.82)$ & $2.4(1.91)$ \\
\hline Motor function L lower extremity (normal $=5$ ) & $2.7(1.81)$ & $2.7(2.03)$ & $2.7(2.23)$ \\
\hline DTR upper extremity (normal =4) & $3.6(0.95)$ & $3.3(1.22)$ & $3.6(0.79)$ \\
\hline DTR lower extremity (normal =4) & $2.4(1.35)$ & $2.1(1.62)$ & $2.3(1.61)$ \\
\hline Babinski sign $L$ side (absent $=2$ ) & $0.6(0.94)$ & $0.9(1.02)$ & $0.7(0.99)$ \\
\hline Babinski sign $\mathrm{R}$ side (absent $=2$ ) & $0.8(1.01)$ & $0.8(1.01)$ & $0.5(0.87)$ \\
\hline Sensory R upper extremity (normal =3) & $3.0(0.00)$ & $2.7(0.47)$ & $2.8(0.56)$ \\
\hline Sensory L upper extremity (normal $=3$ ) & $3.0(0.00)$ & $2.6(0.50)$ & $2.8(0.56)$ \\
\hline Sensory R lower extremity (normal $=3$ ) & $2.9(0.31)$ & $2.5^{*}(0.51)$ & $2.5^{*}(0.72)$ \\
\hline Sensory L lower extremity (normal = 3) & $2.9(0.31)$ & $2.5^{*}(0.51)$ & $2.5(0.80)$ \\
\hline Cerebellar signs upper extremity (normal $=5$ ) & $4.0(1.52)$ & $4.0(1.52)$ & $4.1(1.60)$ \\
\hline Cerebellar signs lower extremity (normal $=5$ ) & $2.9(1.46)$ & $3.6(1.87)$ & $3.4(1.77)$ \\
\hline Gait trunk and balance (normal $=10$ ) & $5.1(2.74)$ & $5.6(3.17)$ & $4.6(3.69)$ \\
\hline Bladder, bowel, and/or sexual dysfunction (normal $=0$ )* & $-4.7(2.52)$ & $-2.7^{*}(2.89)$ & $-3.1(3.31)$ \\
\hline Total SNRS & $75.0(11.90)$ & $75.5(16.54)$ & $73.5(19.52)$ \\
\hline
\end{tabular}

*Statistically significant change, $p<0.05$ 
SNRS Bladder/bowel/sexual dysfunction

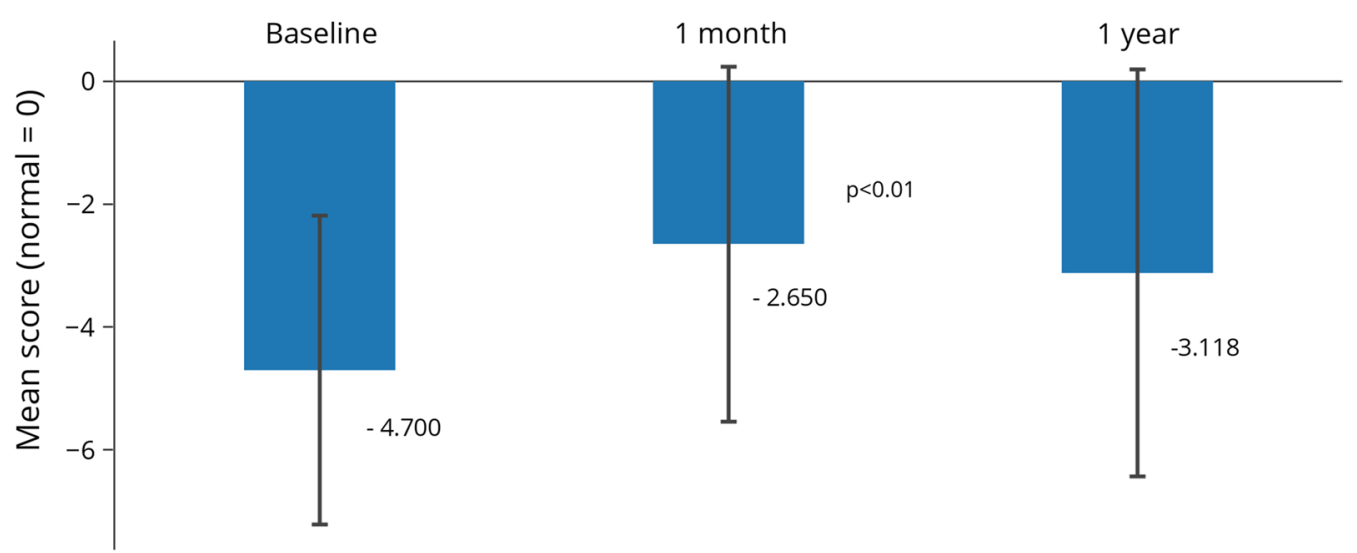

Fig. 2 Scripps Neurological Rating Scale (SNRS) scores. Bladder, bowel and sexual dysfunction SNRS scores. The normal score is 0 . A higher score on the SNRS indicates a higher level of neurological functioning, with possible scores ranging from -10 to $100 . \mathrm{N}=20$ at 1 month (same as baseline), $\mathrm{N}=17$ at 1 year. Statistically significant changes between time points are indicated with their $p$-values

(baseline, 1 month and 1 year), with a statistically significant reduction $(\mathrm{p}<0.02)$ in walk times found between baseline and 1 month (Fig. 4).

Some subjects changed ambulatory status at the time of the 25FWT at the 1-month visit: two subjects reduced their dependence upon assistive devices (one from wheelchair to walker, one from walker to cane); one became more dependent (from no assistance to a cane). At the 1 -year visit, two subjects reduced their dependence upon assistance devices from baseline to 1-year visit (one from wheelchair to walker, one from walker to cane to no assistance); two increased dependency (one from unilateral cane to walker, one from no assistance to cane). One of the subjects, wheelchair-bound at baseline and thus unable to complete the test then, was able to complete it at the 1-month and 1-year follow-ups.

Scores for the RAND SF-36 test were recorded for all subjects at baseline and 1 month, and for 17 of 20 subjects at 1 year post-treatment. Overall, subjects reported improvements in their health during the study. Total QOL scores increased over baseline for 15 subjects at the 1 month follow up visit, while only five decreased. At 1 year, total QOL score improved over baseline for 11 subjects, while six decreased (Fig. 5). At 1 month and 1 year, more than half of the subjects reported their condition as better or the same on all scale scores (Table 5). At 1 month, more than $50 \%$ of subjects reported improvements on five of the eight scale scores (role limitationsphysical, energy/fatigue, emotional well-being, social functioning, and general health), as well as health change; $45 \%(9 / 20)$ of subjects reported improvements in the pain scale, and 35\% (7/20) of subjects reported improvements in their physical functioning and role limitationsemotional. At 1 year, more than half of subjects reported feeling better in five of the eight scales (physical functioning, role limitations-physical, energy/fatigue, emotional wellbeing, and general health), as well as health change; $47 \%(8 / 17)$ reported improvements in their social functioning, 35\% (6/17) in pain scale, and 29\% (5/17) in role limitations-emotional.

Statistically significant changes from baseline occurred at both 1-month and 1-year assessments for the RAND SF-36 role limitations-physical $(\mathrm{p}<0.002$ and $\mathrm{p}<0.03$, respectively) and health change $(\mathrm{p}<0.004$ and $\mathrm{p}<0.02$, respectively) categories. A statistically significant change occurred from baseline at 1 month in the energy category $(\mathrm{p}<0.006)$ and the average score $(\mathrm{p}<0.001)$. Bonferroni corrections retained statistically significant differences at 1 month in these four categories $(\mathrm{p}<0.02)$. Most categories in the RAND SF-36 showed improvement over the baseline at 1 month and 1-year evaluations, with the exception of the 1-month physical function score. Most categories scored highest at the 1-month evaluation with the exception of the physical function category (Fig. 6).

Pre- and post-treatment MRIs from the brain and the cervical spinal cord were reviewed qualitatively for every subject. MRI was unavailable at the 1-year follow-up for two subjects. Not all subjects had the second MRI taken at exactly 1 year after treatment; there was some variation in completion of the second MRI, up to 4 months after the 1-year mark. No common themes were detected regarding number of lesions or disappearance of lesions. Of the 18 subjects that did complete MRI both at baseline and at the 1-year follow-up, 15 (83.3\%) showed no disease progression or no new or active lesions. Two subjects (11.1\%) showed progression in their lesions. One patient (5.6\%) showed near complete resolution of the plaques in the brain, in previously noted areas of 


\section{a}

\section{Best Time (Non-dominant hand)}

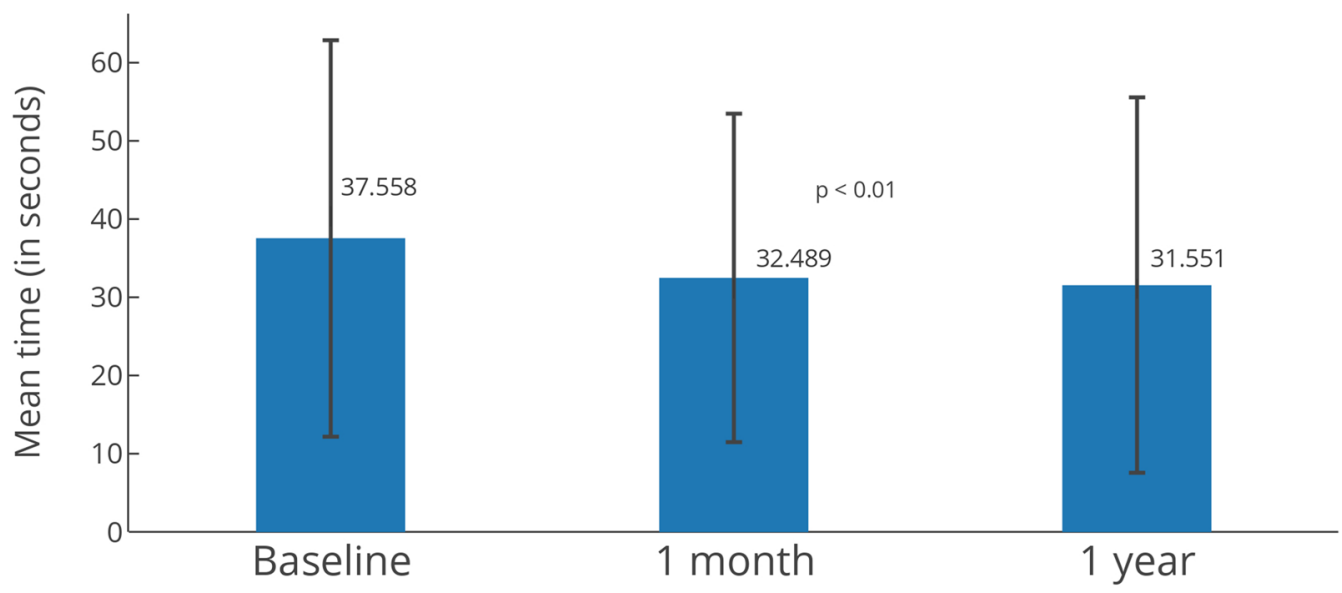

b

Average Time (Non-dominant hand)

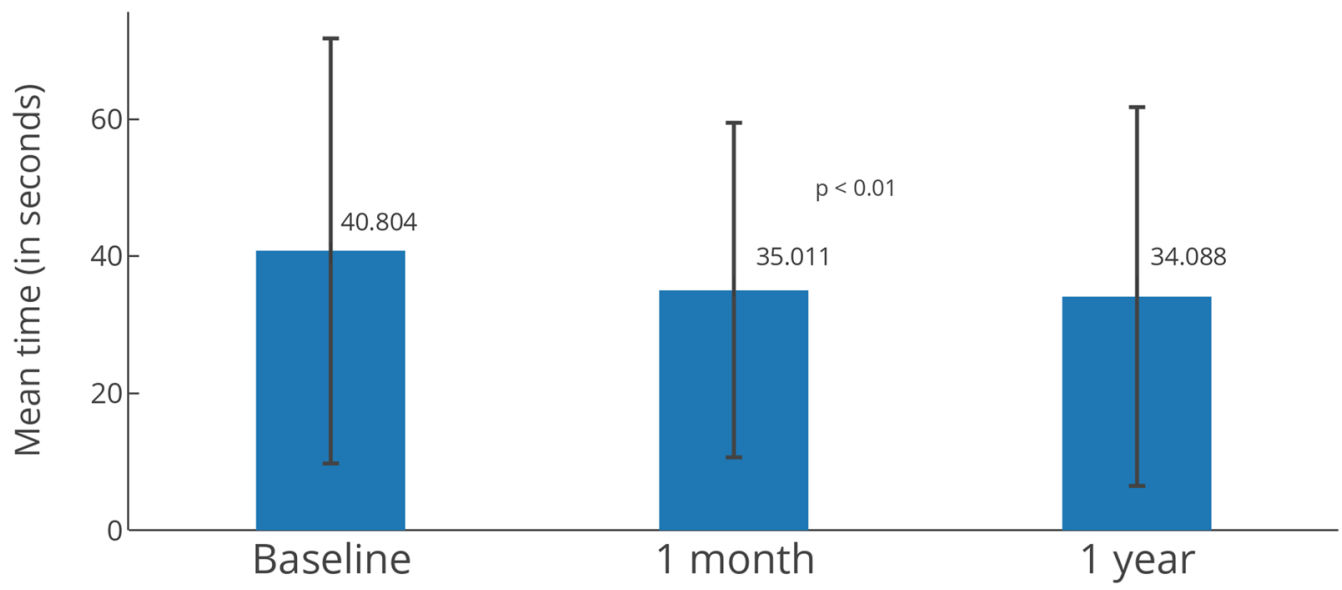

Fig. 3 Nine Hole Peg Test (9HPT) for non-dominant hand. Best (a) and average (b) times for non-dominant hand. The 9HPT is an evaluation of arm/ upper extremity functionality or disability. A reduction in the test time from the reference time point signifies an improvement of upper extremity function. $\mathrm{N}=20$ at 1 month (same as baseline), $N=19$ at 1 year. Statistically significant changes between time points are indicated with their p-values. Error bars represent standard deviations

Table 4 25-Foot Walk Test times

\begin{tabular}{lllll}
\hline & Trial 1-average time & Trial 2-average time & Overall mean time & Average minimum time \\
\hline Baseline & $17.43(\mathrm{~N}=18)$ & $17.51(\mathrm{~N}=18)$ & $17.47(\mathrm{~N}=18)$ & $15.85(\mathrm{~N}=18)$ \\
1 month & $29.19(\mathrm{~N}=18)$ & $11.50(\mathrm{~N}=13)$ & $28.63(\mathrm{~N}=18)$ & $28.01(\mathrm{~N}=18)$ \\
1 year & $16.18(\mathrm{~N}=15)$ & $13.29(\mathrm{~N}=13)$ & $15.70(\mathrm{~N}=15)$ & $14.71(\mathrm{~N}=15)$ \\
\hline
\end{tabular}

abnormal signal intensity consistent with demyelinating disease (Fig. 7).

\section{Discussion}

The demographics of this study correspond to those of an expected MS population, where women are typically affected twice as frequently as men, and most patients are diagnosed between 20 and 40 years of age [26-29].
No Serious Adverse Events occurred in the study. One single Adverse Event (AE), headache, was noted as probably related to treatment. Of the AEs denoted as possibly related to treatment, most were headache or fatigue. Headache is a known complaint noted to occur during or just after MSC infusions, most of which quickly resolve [30]. Additionally, Foley et al demonstrated that patients with MS commonly experience headache [31]. Thus, 


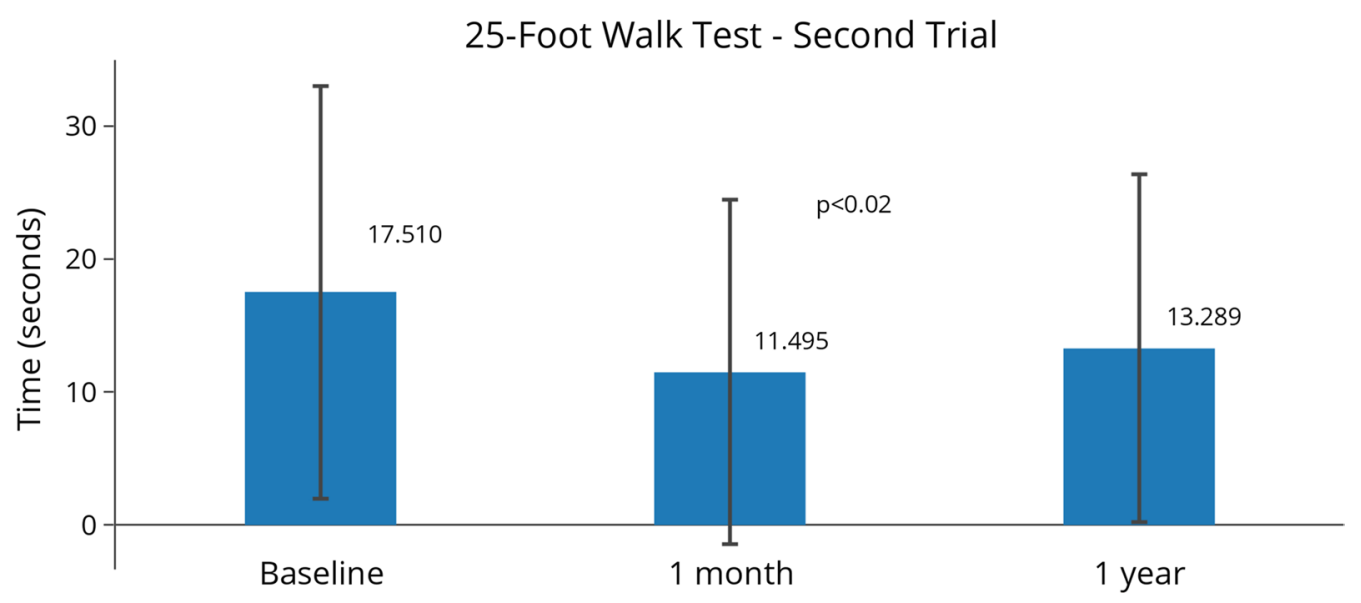

Fig. 425 Foot Walk Test (25FWT) 2nd trial scores. Subjects were asked to perform two trials of a 25-Foot Walk. Not all subjects completed both trials, or performed these tests at all time points. In this figure $\mathrm{N}=12$, and statistically significant changes between time points are indicated with their p-values. Error bars represent standard deviations

\section{Changes in Quality of Life (SF-36) Total Score}

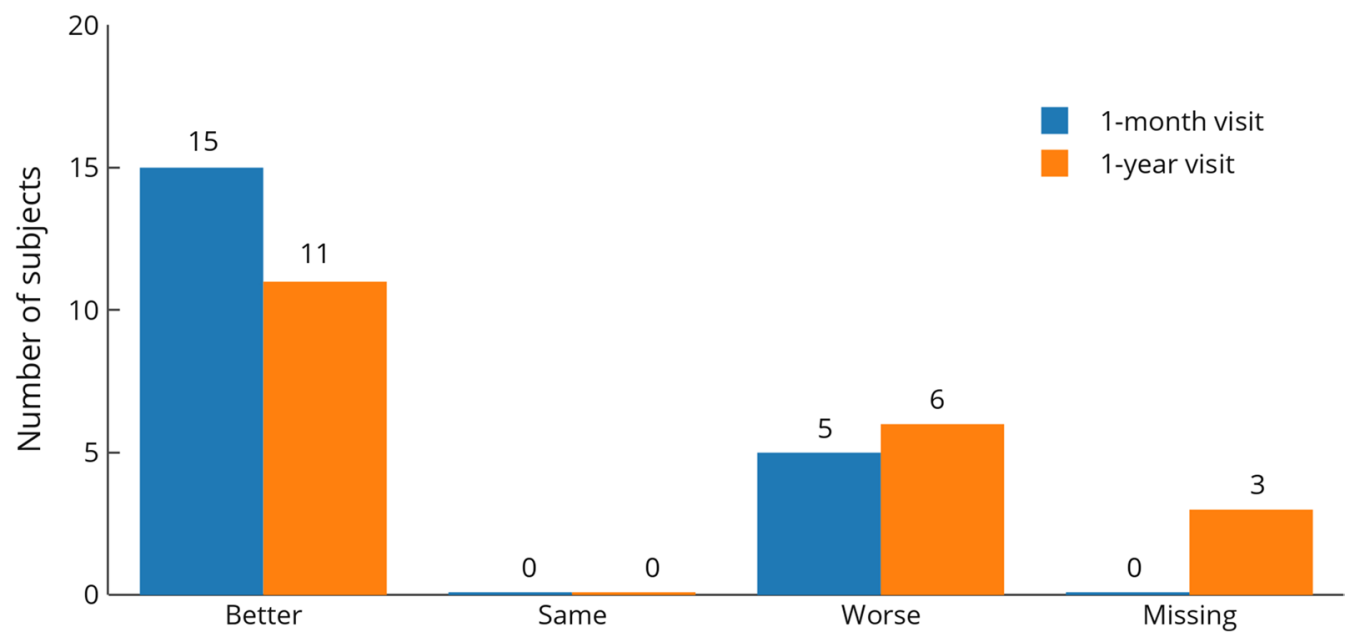

Fig. 5 RAND SF-36 quality of life scores compared to baseline. Scores for the RAND SF-36 question capture health change. Scores were compared with baseline at the 1 -month and 1 -year visits. $N=20$ at 1 month (same as baseline), $N=17$ at 1 year

headache is not unexpected at the time of or just after UCMSC infusions. Similarly, fatigue is one of the most common complaints [32]. Fatigue appears in all ages and phenotypes of MS [33-35] and is a primary determinant of poor QOL [35], affecting both physical and mental components independent of disability level [34]. Thus, although fatigue is a possibly related $\mathrm{AE}$ in this study, it is also a very common disability symptom of MS.

Enrolled subjects experienced an improvement in their symptoms, which was most notable at 1 month after treatment, and was sustained at 1 year in some cases (Table 6). The potential durable benefit of UCMSC at 1 month, and sustained in some measures to 1 year, is in stark contrast to current MS drug therapies, which are required to be taken daily or weekly [36]. In addition, MS drugs are known to carry side effects [37] not seen after UCMSC infusions up to 1-year after treatment.

Previous studies using MSC treatment for MS have reported improvements in EDSS scores [19, 22, 23, 38, 39]. In our case, the statistically significant $(p<0.03)$ change in EDSS mean scores from baseline to 1 month reflects a change in disability category, which could translate into an improved ability to walk and work a full day with minimal, if any, assistance. Although other categories showed worsening typical of disease progression, the bladder/bowel/sexual dysfunction category of the SNRS showed statistically significant improvement at 1 month $(\mathrm{p}<0.05)$. This finding may be encouraging in that up to 
Table 5 RAND SF-36 changes in scores

\begin{tabular}{|c|c|c|c|c|c|c|}
\hline & \multicolumn{3}{|c|}{ Baseline to 1 month $(\mathrm{N}=20)$} & \multicolumn{3}{|c|}{ Baseline to 1 year $(\mathrm{N}=17)$} \\
\hline & Better & Same & Worse & Better & Same & Worse \\
\hline Physical functioning & $7(35 \%)$ & $4(20 \%)$ & $9(45 \%)$ & $10(59 \%)$ & $1(6 \%)$ & $6(35 \%)$ \\
\hline Role limitations_- physical $^{a}$ & $13(65 \%)$ & $6(30 \%)$ & $1(5 \%)$ & $11(65 \%)$ & $4(24 \%)$ & $2(12 \%)$ \\
\hline Role limitations_emotional & $7(35 \%)$ & $10(50 \%)$ & $3(15 \%)$ & $5(29 \%)$ & $9(53 \%)$ & $3(18 \%)$ \\
\hline Energy/fatigue ${ }^{b}$ & $16(80 \%)$ & $1(5 \%)$ & $3(15 \%)$ & $11(65 \%)$ & $0(0 \%)$ & $6(35 \%)$ \\
\hline Emotional well-being & $13(65 \%)$ & $2(10 \%)$ & $5(25 \%)$ & $10(59 \%)$ & $2(12 \%)$ & $5(29 \%)$ \\
\hline Social functioning & $12(60 \%)$ & $2(10 \%)$ & $6(30 \%)$ & $8(47 \%)$ & $1(6 \%)$ & $8(47 \%)$ \\
\hline Pain & $9(45 \%)$ & $5(25 \%)$ & $6(30 \%)$ & $6(35 \%)$ & $8(47 \%)$ & $3(18 \%)$ \\
\hline General health & $11(55 \%)$ & $1(5 \%)$ & $8(40 \%)$ & $9(53 \%)$ & $2(12 \%)$ & $6(35 \%)$ \\
\hline Health change $\mathrm{a}^{\mathrm{a}}$ & $13(65 \%)$ & $6(30 \%)$ & $1(5 \%)$ & $11(65 \%)$ & $4(24 \%)$ & $2(12 \%)$ \\
\hline
\end{tabular}

a Differences between baseline and 1-month and 1-year scores statistically significant $(p<0.03)$

b Differences between baseline and 1-month scores statistically significant $(p<0.001)$

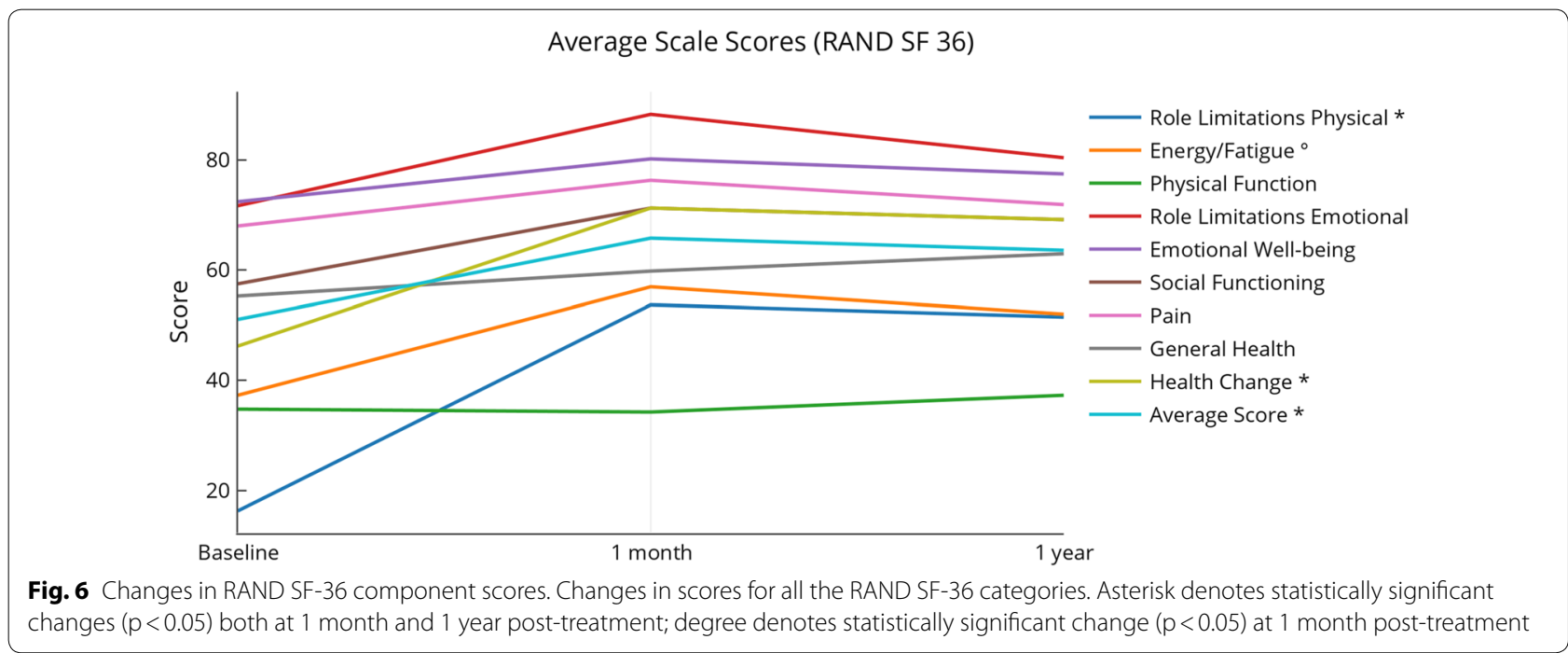

$60 \%$ of patients with MS report sexual dysfunction problems [40] while over 50\% experience bowel dysfunction and up to $75 \%$ will report bladder dysfunction [41].

Changes to ambulatory status from baseline classifications were noteworthy in this study for the 25FWT. Increasing disability (e.g., going from unassisted walking to a cane) is a typical disease progression in the MS population in general, but the reverse would not be expected. However, subjects in our study improved from wheelchair status to using a walker, and from walker status to requiring no assistance.

In general, QOL for patients with MS is diminished by physical, emotional, and cognitive symptoms and comorbidities [33, 42]. However, subjects enrolled in this study reported consistent improvements in their RAND 36 SF QOL in these areas, particularly at the 1-month evaluation $(\mathrm{p}<0.001)$. Most categories improved at 1 month, and then slipped slightly at the 1 year evaluation period while still remaining improved over baseline, suggesting that treatment frequency greater than once annually could further improve the treatment subject's QOL outlook.

Most subjects (83.3\%) showed no disease progression or new lesions in their MRIs. The near complete resolution of the plaques of the brain in one patient (Fig. 7) is a particularly encouraging finding that should be further investigated by comparing it to similar MS cohorts in a standardized time period.

The small sample size is the most significant limitation of this study in that it may impact the statistical significance of the results. When subjects were lost to followup, the sample size was reduced; due to the nature of certain tests used to measure efficacy signals, failing to complete one part of the test often invalidated obtaining an average for the score. While this issue could have been avoided with larger recruitment numbers, we are still in the lower threshold of the $20-80$ subjects recommended 


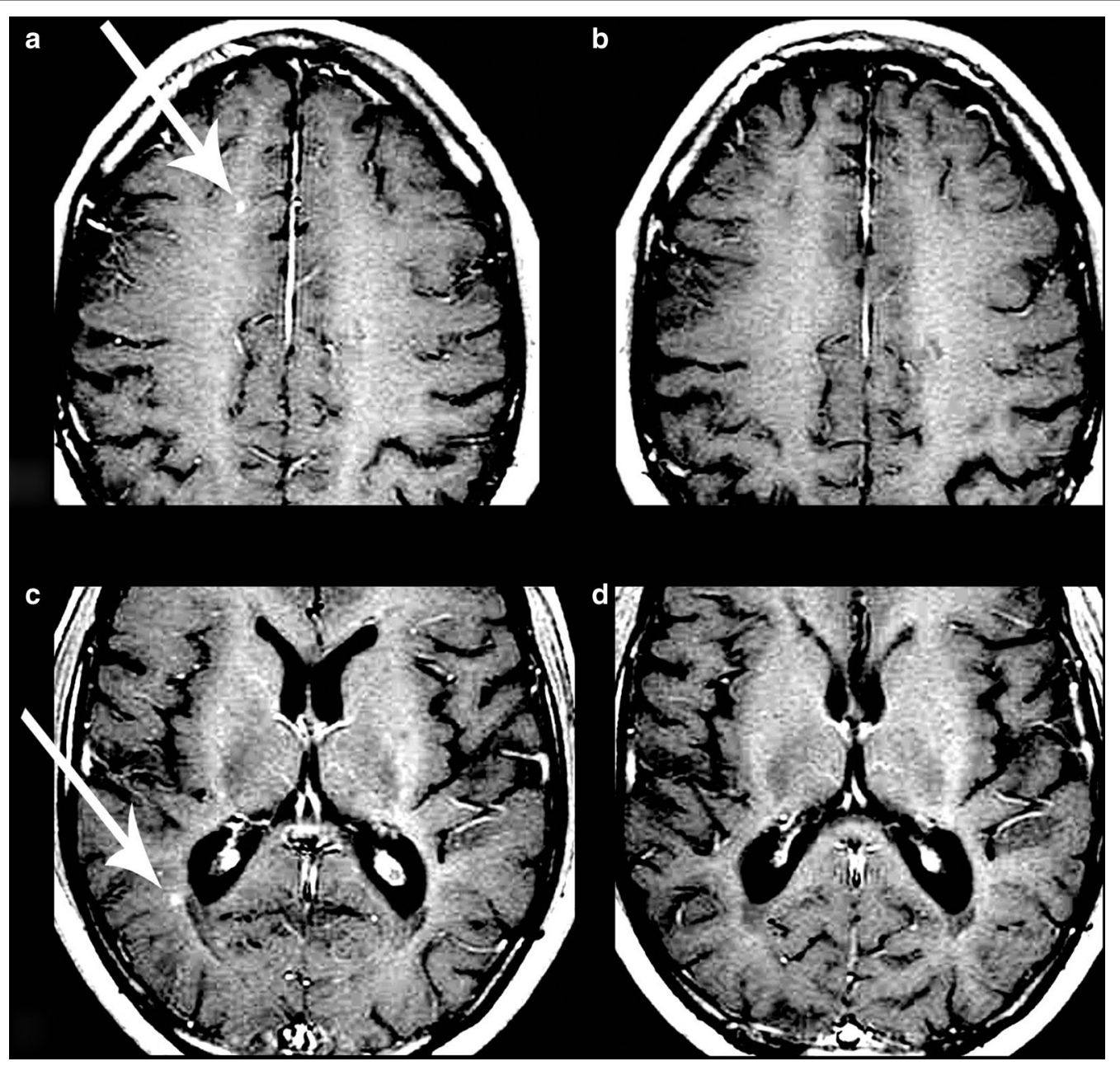

Fig. 7 Changes in magnetic resonance imaging (MRI) before and after treatment. Gadolinium-enhanced MRI scans of the brain for one subject before ( $\mathbf{a}$ and $\mathbf{c}$ ) and after ( $\mathbf{b}$ and $\mathbf{d}$ ) treatment. Lesions of interest are indicated by a white arrow. $\mathbf{b}$ Interval resolution of a lesion in the right frontal juxtacortical white matter (a). $\mathbf{d}$ Interval resolution of a lesion in the right periatrial white matter (c). Names and other personal information have been edited out of the images

by FDA for early trials. Additionally, subjects with certain forms of MS may be less likely to develop new lesions, which may impact the findings of the reported MRI results. As this was primarily a safety and proof of concept trial, we did not require subjects to stop their usual

\section{Table 6 Summary of efficacy assessment scores}

\begin{tabular}{lccc}
\hline Test & Baseline & $\mathbf{1}$ month & 1 year \\
\hline EDSS mean scores & 5.2 & $4.8^{*}$ & $4.5^{*}$ \\
$\begin{array}{l}\text { SNRS bladder/bowel/sexual dys- } \\
\quad-4.7\end{array}$ & $-2.7^{*}$ & -3.1 \\
$\begin{array}{l}\text { Nine Hole Peg Test-non-domi- } \\
\quad \text { nant hand average scores }\end{array}$ & 35.1 & $30.2^{*}$ & 34.1 \\
$\begin{array}{l}\text { 25-foot walk (second trial) times } \\
\text { RAND SF-36 average scale }\end{array}$ & 17.5 & $11.5^{*}$ & 13.3 \\
\hline
\end{tabular}

${ }^{*} p<0.05$ when compared to baseline; ${ }^{* * *} p<0.001$ when compared to baseline medications, which could have a confounding impact on our findings. Poor medication adherence is frequently seen among patients with MS (usually because of cost, perceived lack of efficacy, or adverse effects) [43]; in our sample, $25 \%$ were not taking any MS-specific medication at the start of treatment. However, it is noteworthy that a further $20 \%$ felt well enough to reduce their intake. In any case, efficacy of UCMSC therapy for MS should be confirmed with larger, controlled, randomized trials.

\section{Conclusions}

We have shown that the intravenous infusion of UCMSC over several days is safe in subjects with MS. Additionally, UCMSC infusions may hold benefits, since this small study group saw improvement in bladder, bowel, and sexual dysfunction, walking, upper extremity physical 
function, energy and fatigue, general perspective of a positive health change and improved quality of life, and MRI lesions. More clinical studies, particularly with a larger cohort, are needed to substantiate the specific benefits of UCMSC infusion as a potential MS therapy.

\section{Authors' contributions}

JPR, NHR, NF, and ML designed the study. JPR, IM, and GF supervised the study. $\mathrm{GF}, \mathrm{NF}, \mathrm{ML}, \mathrm{DaM}$, and DeM were involved in data collection, NA in data management, and IM in project management. DeM and DaM were clinical monitors and audited treatment and follow-up assessments. DeM was involved in compilation, record keeping, and statistical summaries. NF, ML, DaM and DeM performed the statistical analysis, and interpreted the data. NF, ML, DaM, DeM, DA, SK, and NHR searched the literature. NF, ML, and DeM wrote and edited the first draft of this manuscript, organized the manuscript layout, and created the figures. DA edited this manuscript to its final form and revised the figures. SK and ANP reviewed the analyses and manuscript, and provided academic feedback. All authors provided feedback and helped shape the research, analysis and manuscript. All authors read and approved the final manuscript.

\section{Author details}

${ }^{1}$ Stem Cell Institute, Panama City, Panama. ${ }^{2}$ MediStem Panama Inc., Clayton, City of Knowledge, Panama City, Panama. ${ }^{3}$ Cook Advanced Technologies, West Lafayette, IN, USA. ${ }^{4}$ Cook Medical Technologies, Bloomington, IN, USA. ${ }^{5}$ Department of Surgery, University of Miami School of Medicine, Miami, FL, USA. ${ }^{6}$ Department of Translational Neurosciences and Neurotherapeutics, John Wayne Cancer Institute and Pacific Neuroscience Institute, Santa Monica, CA, USA.

\section{Acknowledgements}

The authors would like to thank Jay Lenner for management and updating study information on clinicaltrials.gov, as well as MediStem Panama and Stem Cell Institute staff for their laboratory, medical and administrative assistance.

\section{Competing interests}

NHR and JPR are shareholders of Translational Biosciences, MediStem Panama, and the Stem Cell Institute. The authors declare that they have no competing interests.

\section{Availability of data and materials}

The datasets generated and/or analyzed during the current study are available from the corresponding author on reasonable request.

\section{Ethics approval and consent to participate}

The study was approved by the Panamanian Institutional Review Board (Comité Nacional de Ética de la Investigación, IORG0007644) under Protocol Number TBS-UCMSC-001. The study was designed in the spirit of ethical principles with origin in the Declaration of Helsinki or equivalent, and consistent with Good Clinical Practices. All subjects and donors gave informed consent to participate in the study.

\section{Consent for publication}

Not applicable.

\section{Funding}

The study sponsor was Translational Biosciences. The study sponsor had no role in the design of this study, its execution, analysis, interpretation of the data, writing, or decision to submit results.

\section{Publisher's Note}

Springer Nature remains neutral with regard to jurisdictional claims in published maps and institutional affiliations.

Received: 16 January 2018 Accepted: 2 March 2018

Published online: 09 March 2018

\section{References}

1. Navikas V, Link H. Review: cytokines and the pathogenesis of multiple sclerosis. J Neurosci Res. 1996;45:322-33.

2. Ghasemi N, Razavi S, Nikzad E. Multiple sclerosis: pathogenesis, symptoms, diagnoses and cell-based therapy. Cell J. 2017;19:1-10.

3. Marrie RA, Elliott L, Marriott J, Cossoy M, Blanchard J, Leung S, Yu N. Effect of comorbidity on mortality in multiple sclerosis. Neurology. 2015;85:240-7.

4. Ernstsson O, Gyllensten $\mathrm{H}$, Alexanderson $\mathrm{K}$, Tinghög P, Friberg E, Norlund A. Cost of illness of multiple sclerosis-a systematic review. PLoS ONE. 2016;11:e0159129.

5. Rodgers JM, Robinson AP, Miller SD. Strategies for protecting oligodendrocytes and enhancing remyelination in multiple sclerosis. Discov Med. 2013;16:53-63.

6. Zannettino AC, Paton S, Arthur A, Khor F, Itescu S, Gimble JM, Gronthos $S$. Multipotential human adipose-derived stromal stem cells exhibit a perivascular phenotype in vitro and in vivo. J Cell Physiol. 2008:214:413-21.

7. Hoogduijn MJ, Crop MJ, Peeters AM, Van Osch GJ, Balk AH, ljzermans JN, Weimar W, Baan CC. Human heart, spleen, and perirenal fat-derived mesenchymal stem cells have immunomodulatory capacities. Stem Cells Dev. 2007;16:597-604.

8. Chao KC, Chao KF, Fu YS, Liu SH. Islet-like clusters derived from mesenchymal stem cells in Wharton's Jelly of the human umbilical cord for transplantation to control type 1 diabetes. PLOS ONE. 2008;3:e1451.

9. Jo YY, Lee HJ, Kook SY, Choung HW, Park JY, Chung JH, Choung YH, Kim ES, Yang HC, Choung PH. Isolation and characterization of postnatal stem cells from human dental tissues. Tissue Eng. 2007;13:767-73.

10. He Q, Wan C, Li G. Concise review: multipotent mesenchymal stromal cells in blood. Stem Cells. 2007;25:69-77.

11. Liu R, Zhang Z, Lu Z, Borlongan C, Pan J, Chen J, Qian L, Liu Z, Zhu L, Zhang J, Xu Y. Human umbilical cord stem cells ameliorate experimental autoimmune encephalomyelitis by regulating immunoinflammation and remyelination. Stem Cells Dev. 2013;22:1053-62.

12. Wang LT, Ting CH, Yen ML, Liu KJ, Sytwu HK, Wu KK, Yen BL. Human mesenchymal stem cells (MSCs) for treatment towards immune- and inflammation-mediated diseases: review of current clinical trials. J Biomed Sci. 2016:23:76.

13. Weiss ML, Medicetty S, Bledsoe AR, Rachakatla RS, Choi M, Merchav S, Luo Y, Rao MS, Velagaleti G, Troyer D. Human umbilical cord matrix stem cells: preliminary characterization and effect of transplantation in a rodent model of Parkinson's disease. Stem Cells. 2006;24:781-92.

14. Najar M, Raicevic G, Boufker HI, Fayyad Kazan H, De Bruyn C, Meuleman N, Bron D, Toungouz M, Lagneaux L. Mesenchymal stromal cells use PGE2 to modulate activation and proliferation of lymphocyte subsets: combined comparison of adipose tissue, Wharton's Jelly and bone marrow sources. Cell Immunol. 2010;264:171-9.

15. Madrigal M, Rao KS, Riordan NH. A review of therapeutic effects of mesenchymal stem cell secretions and induction of secretory modification by different culture methods. J Transl Med. 2014;12:260.

16. Ardeshiry Lajimi A, Hagh MF, Saki N, Mortaz E, Soleimani M, Rahim F. Feasibility of cell therapy in multiple sclerosis: a systematic review of 83 studies. Int J Hematol Oncol Stem Cell Res. 2013:7:15-33.

17. Connick P, Kolappan M, Crawley C, Webber DJ, Patani R, Michell AW, Du MQ, Luan SL, Altmann DR, Thompson AJ, et al. Autologous mesenchymal stem cells for the treatment of secondary progressive multiple sclerosis: an open-label phase 2a proof-of-concept study. Lancet Neurol. 2012;11:150-6.

18. Dulamea A. Mesenchymal stem cells in multiple sclerosis-translation to clinical trials. J Med Life. 2015:8:24-7.

19. Hou ZL, Liu Y, Mao XH, Wei CY, Meng MY, Liu YH, Zhuyun Yang Z, Zhu H, Short M, Bernard C, Xiao ZC. Transplantation of umbilical cord and bone marrow-derived mesenchymal stem cells in a patient with relapsingremitting multiple sclerosis. Cell Adhes Migr. 2013;7:404-7.

20. Dahbour S, Jamali F, Alhattab D, Al-Radaideh A, Ababneh O, Al-Ryalat $\mathrm{N}$, Al-Bdour M, Hourani B, Msallam M, Rasheed M, et al. Mesenchymal stem cells and conditioned media in the treatment of multiple sclerosis patients: clinical, ophthalmological and radiological assessments of safety and efficacy. CNS Neurosci Ther. 2017;23:866-74.

21. Riordan NH, Ichim TE, Min WP, Wang H, Solano F, Lara F, Alfaro M, Rodriguez JP, Harman RJ, Patel AN, et al. Non-expanded adipose 
stromal vascular fraction cell therapy for multiple sclerosis. J Transl Med. 2009;7:29.

22. Lublin FD, Bowen JD, Huddlestone J, Kremenchutzky M, Carpenter A, Corboy JR, Freedman MS, Krupp L, Paulo C, Hariri RJ, Fischkoff SA. Human placenta-derived cells (PDA-001) for the treatment of adults with multiple sclerosis: a randomized, placebo-controlled, multiple-dose study. Mult Scler Relat Disord. 2014;3:696-704.

23. Li JF, Zhang DJ, Geng T, Chen L, Huang H, Yin HL, Zhang YZ, Lou JY, Cao B, Wang YL. The potential of human umbilical cord-derived mesenchymal stem cells as a novel cellular therapy for multiple sclerosis. Cell Transplant. 2014;23(Suppl 1):S113-22.

24. Polman CH, Reingold SC, Banwell B, Clanet M, Cohen JA, Filippi M, Fujihara K, Havrdova E, Hutchinson M, Kappos L, et al. Diagnostic criteria for multiple sclerosis: 2010 revisions to the McDonald criteria. Ann Neurol. 2011;69:292-302.

25. Dominici M, Le Blanc K, Mueller I, Slaper-Cortenbach I, Marini F, Krause D, Deans R, Keating A, Prockop D, Horwitz E. Minimal criteria for defining multipotent mesenchymal stromal cells. The international society for cellular therapy position statement. Cytotherapy. 2006;8:315-7.

26. Hauser S, Goodwin D. Multiple sclerosis and other demyelinating diseases. In Harrison's principles of internal medicine. 17th ed. New York: McGraw-Hill Medical; 2008. p. 2611-21.

27. Cree B. Multiple sclerosis. In: Brust J, editor. Current Diagnosis and Treatment in Neurology. New York: Lange Medical Books/McGraw-Hill Medical; 2007.

28. Kantarci O, Wingerchuk D. Epidemiology and natural history of multiple sclerosis: new insights. Curr Opin Neurol. 2006:19:248-54.

29. Evans C, Beland SG, Kulaga S, Wolfson C, Kingwell E, Marriott J, Koch M, Makhani N, Morrow S, Fisk J, et al. Incidence and prevalence of multiple sclerosis in the Americas: a systematic review. Neuroepidemiology. 2013:40:195-210

30. Karussis D, Karageorgiou C, Vaknin-Dembinsky A, Gowda-Kurkalli B, Gomori JM, Kassis I, Bulte JW, Petrou P, Ben-Hur T, Abramsky O, Slavin S. Safety and immunological effects of mesenchymal stem cell transplantation in patients with multiple sclerosis and amyotrophic lateral sclerosis. Arch Neurol. 2010;67:1187-94

31. Foley PL, Vesterinen HM, Laird BJ, Sena ES, Colvin LA, Chandran S, MacLeod MR, Fallon MT. Prevalence and natural history of pain in adults with multiple sclerosis: systematic review and meta-analysis. Pain. 2013;154:632-42.

32. Induruwa I, Constantinescu CS, Gran B. Fatique in multiple sclerosis-a brief review. J Neurol Sci. 2012;323:9-15.

33. Zwibel HL, Smrtka J. Improving quality of life in multiple sclerosis: an unmet need. Am J Manag Care. 2011;17(Suppl 5):S139-45.

34. Zwibel HL. Contribution of impaired mobility and general symptoms to the burden of multiple sclerosis. Adv Ther. 2009;26:1043-57.

35. Ziemssen T. Multiple sclerosis beyond EDSS: depression and fatigue. J Neurol Sci. 2009;277(Suppl 1):S37-41.

36. Hartung DM, Bourdette DN, Ahmed SM, Whitham RH. The cost of multiple sclerosis drugs in the US and the pharmaceutical industry: too big to fail? Neurology. 2015;84:2185-92.

37. Wingerchuk DM, Carter JL. Multiple sclerosis: current and emerging disease-modifying therapies and treatment strategies. Mayo Clin Proc. 2014:89:225-40.

38. Yamout B, Hourani R, Salti H, Barada W, El-Hajj T, Al-Kutoubi A, Herlopian A, Baz EK, Mahfouz R, Khalil-Hamdan R, et al. Bone marrow mesenchymal stem cell transplantation in patients with multiple sclerosis: a pilot study. J Neuroimmunol. 2010:227:185-9.

39. Bonab MM, Sahraian MA, Aghsaie A, Karvigh SA, Hosseinian SM, Nikbin B, Lotfi J, Khorramnia S, Motamed MR, Togha M, et al. Autologous mesenchymal stem cell therapy in progressive multiple sclerosis: an open label study. Curr Stem Cell Res Ther. 2012;7:407-14.

40. Celik DB, Poyraz EC, Bingöl A, Idiman E, Ozakbas S, Kaya D. Sexual dysfunction in multiple sclerosis: gender differences. J Neurol Sci. 2013:324:17-20.

41. Betts CD, D'Mellow MT, Fowler CJ. Urinary symptoms and the neurological features of bladder dysfunction in multiple sclerosis. J Neurol Neurosurg Psychiatry. 1993;56:245-50.

42. Crayton H, Heyman RA, Rossman HS. A multimodal approach to managing the symptoms of multiple sclerosis. Neurology. 2004;63:512-8.

43. Menzin J, Caon C, Nichols C, White LA, Friedman M, Pill MW. Narrative review of the literature on adherence to disease-modifying therapies among patients with multiple sclerosis. J Manag Care Pharm. 2013;19:S24-40.

\section{Submit your next manuscript to BioMed Central} and we will help you at every step:

- We accept pre-submission inquiries

- Our selector tool helps you to find the most relevant journal

- We provide round the clock customer support

- Convenient online submission

- Thorough peer review

- Inclusion in PubMed and all major indexing services

- Maximum visibility for your research

Submit your manuscript at www.biomedcentral.com/submit
(OioMed Central 